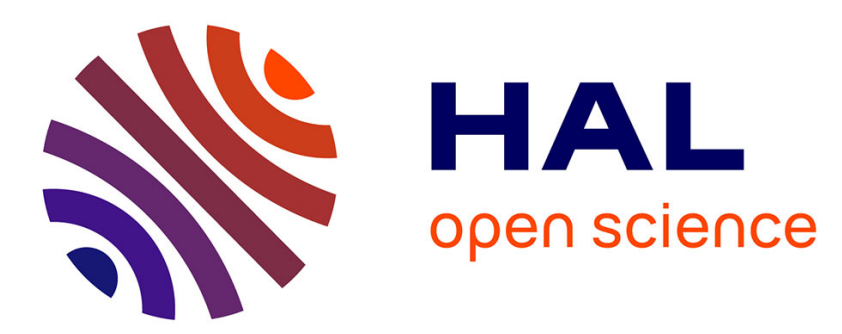

\title{
On the interpretation of intensity anomalies in dense aluminium plasmas
}

\author{
G. Jamelot, A. Carillon, P. Jaeglé, A. Sureau
}

\section{To cite this version:}

G. Jamelot, A. Carillon, P. Jaeglé, A. Sureau. On the interpretation of intensity anomalies in dense aluminium plasmas. Journal de Physique Lettres, 1975, 36 (12), pp.293-295. 10.1051/jphyslet:019750036012029300 . jpa-00231212

\section{HAL Id: jpa-00231212 https://hal.science/jpa-00231212}

Submitted on 1 Jan 1975

HAL is a multi-disciplinary open access archive for the deposit and dissemination of scientific research documents, whether they are published or not. The documents may come from teaching and research institutions in France or abroad, or from public or private research centers.
L'archive ouverte pluridisciplinaire HAL, est destinée au dépôt et à la diffusion de documents scientifiques de niveau recherche, publiés ou non, émanant des établissements d'enseignement et de recherche français ou étrangers, des laboratoires publics ou privés. 


\title{
ON THE INTERPRETATION OF INTENSITY ANOMALIES IN DENSE ALUMINIUM PLASMAS
}

\author{
G. JAMELOT, A. CARILLON, P. JAEGLÉ and A. SUREAU \\ E.R. C.N.R.S. 184, Spectroscopie Atomique et Ionique, Bâtiment 350, \\ Université Paris Sud, 91405 Orsay, France
}

(Reçu le 4 juillet 1975, révisé le 29 septembre 1975, accepté le 7 octobre 1975)

\begin{abstract}
Résumé. - On utilise un modèle numérique pour calculer l'émission et l'absorption de raies discrètes dans des plasmas non homogènes en supposant des populations à l'équilibre. Il est montré que ce modèle ne rend pas compte de résultats expérimentaux concernant trois raies particulières de l'ion $\mathrm{Al}^{3+}$ dans un plasma laser. La surpopulation de l'un des niveaux excités de l'ion $\mathrm{Al}^{3+}$ peut être expliquée par une recombinaison diélectronique faisant intervenir un niveau autoionisant observable expérimentalement.
\end{abstract}

\begin{abstract}
A numerical model is used to predict the behaviour of discrete emission and absorption spectra in non-homogeneous plasmas when the populations are in equilibrium. The evidence of a disagreement between this prediction and experiment is given for three peculiar lines of the $\mathrm{Al}^{3+}$ ion in a laser produced plasma. Dielectronic recombination is invoked as a likely channel leading to an extra population for one of the excited levels of the $\mathrm{Al}^{3+}$ ion. This conjecture is supported by the experimental observations.
\end{abstract}

Spectral features of the $\mathrm{Al}^{3+}$ ions spectrum in a dense laser produced plasma have been discussed in terms of population inversion between electronic levels involved in transitions lying in the X-UV range [1-5]. Recently we showed, by photoabsorption measurements in a two plasma experiment, the occurrence of a negative absorption at the wavelength of $117.41 \AA$ corresponding to the

$$
2 \mathrm{~s}^{2} 2 \mathrm{p}^{5} 4 \mathrm{~d}^{3} \mathrm{P}_{1}-2 \mathrm{~s}^{2} 2 \mathrm{p}^{6}{ }^{1} \mathrm{~S}_{0}
$$

transition in $\mathrm{Al}^{3+}$ ions $[6,7]$. Among the mechanisms able to increase the population of the $2 s^{2} 2 p^{5} 4 d^{3} P_{1}$ level, possibly up to an inversion with respect to the ground state of the ion, we discussed dielectronic recombination (inverse of autoionization) involving the $2 s 2 p^{6} 4 p^{3} P_{1}$ level followed by a collisional transfer to the $2 s^{2} 2 p^{5} 4 d^{3} P_{1}$ level $[2,3]$. This was first suggested by quantum mechanical calculations [8] and was supported by an experimental study of the spectrum showing the autoionizing series $2 s^{2} 2 p^{6} n p$ levels to be very close to the predicted energy values [2].

In a paper of F. P. J. Valero [9] it has been proposed to explain the very anomalous intensities of the $2 \mathrm{p}^{5} 4 \mathrm{~d}^{1} \mathrm{P}_{1},{ }^{3} \mathrm{D}_{1},{ }^{3} \mathrm{P}_{1} \rightarrow 2 \mathrm{p}^{6}{ }^{1} \mathrm{~S}_{0}$ lines [7] by the reabsorption of the ${ }^{1} \mathrm{P}_{1}$ and ${ }^{3} \mathrm{D}_{1}$ lines in the cooler regions of the plasma rather than by the anomalous population of the upper levels of the transitions. This interpreta- tion cannot account for the negative absorption exhibited by the ${ }^{3} \mathrm{P}_{1}$ line and we will see in the present paper that more or less reabsorption is insufficient to explain the intensity anomalies themselves. In addition, we will return to the experimental evidence regarding the autoionizing $2 s 2 p^{6} 4 p$ level which has not been observed in [9].

In figure 1 we illustrate some examples of results given by a numerical model we use to predict the behaviour of emission and absorption in discrete transitions for non homogeneous plasmas. In this model the populations of the excited levels are assumed to be controlled by Boltzmann's law and do not present any anomaly. Moreover, as far as only values averaged over the half-width of the line are desired for emission or absorption, the line profiles are approximated to rectangles [5]. Theoretical values [7] of the ${ }^{1} \mathrm{P}_{1},{ }^{3} \mathrm{D}_{1},{ }^{3} \mathrm{P}_{1}$ transition probabilities have been introduced in the calculation. The probability for the ${ }^{3} \mathrm{P}_{1}$ line being about ten times less than for both other lines, this ratio will still apply for the line intensities in the case of thin plasmas, if the lines have the same widths.

The experimental half-widths are of $0.2 \mathrm{eV}$ for the ${ }^{1} P_{1}$ and the ${ }^{3} \mathrm{D}_{1}$ lines, but merely $0.01 \mathrm{eV}$ for the ${ }^{3} \mathrm{P}_{1}$ line [7]. Figure 1 shows that, with such a large difference between the line widths, there is no appreciable 

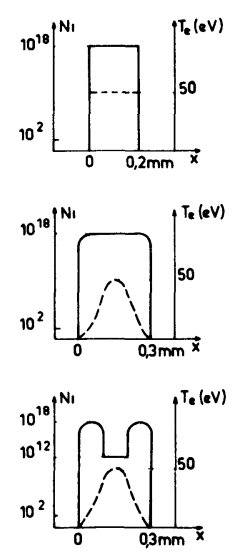

Al $^{3+}$ ION DENSITY Ni ELECTRONIC TEMPERATURE T. - -

Line widths. Spontoneous entsol

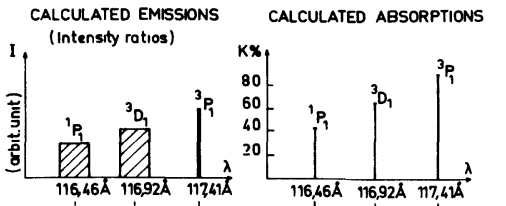

FIG. 1. - Theoretical emission intensity and absorption for $2 \mathrm{p}^{6}{ }^{1} \mathrm{~S}_{0}-2 \mathrm{p}^{5} 4 \mathrm{~d}^{1} \mathrm{P}_{1},{ }^{3} \mathrm{D}_{1},{ }^{3} \mathrm{P}_{1}$ transitions of $\mathrm{Al}^{3+}$ ions in the case of populations in equilibrium. The emitted intensities are proportional to the dashed rectangular surfaces. Experimental half-widths, of respectively $0: 2 \mathrm{eV}, 0.2 \mathrm{eV}, 0.01 \mathrm{eV}$ and theoretical spontaneous emission coefficient, of respectively $9.88 \times 10^{9} \mathrm{~s}^{-1}, 17.58 \times 10^{9} \mathrm{~s}^{-1}$ and $1.98 \times 10^{9} \mathrm{~s}^{-1}$, are introduced in the calculation. Due to the large influence of the line width a cold external shell of plasma does not change strongly the intensity ratios.

influence of the reabsorption in the cold external shell of the plasma upon the intensity ratio of the three lines. The upper part of the figure presents the case of a quasihomogeneous plasma, without a cold external shell. Thus, the intensities could be calculated $[4,5]$ by the relation :

$$
\begin{aligned}
I=\frac{2 h v^{3}}{c^{2}} \frac{N_{2}}{N_{1}-} & N_{2} \\
\times & {\left[1-\exp -\frac{h v}{c} \frac{B_{12}}{\delta v}\left(N_{1}-N_{2}\right) x\right] }
\end{aligned}
$$

where $v$ is the radiation frequency, $\delta v$ the half width of the line, $B_{12}$ the Einstein's coefficient for absorption, $N_{1}$ and $N_{2}$ are respectively the population densities of the lower and upper level (let $g_{1}$ and $g_{2}$ be the statistical weights of levels 1 and 2 ; here $N_{2}$ is written for $\left.\left(g_{1} / g_{2}\right) N_{2}\right)$. In this relation we can see the role of the line width which can compensate either the transition probability or the $\left(N_{1}-N_{2}\right)$ density difference. Indeed, the increase in $\left(N_{1}-N_{2}\right)$ density in external plasma shell, due to the lowering of temperature (middle part of the figure) or to a particular distribution of the ions (lower part of the figure), does not change the broad line intensities significantly as compared to that of the narrow line.

Furthermore, in including Boltzmann's value of the population ratio $N_{2} / N_{1}$ as in the model used here, the calculated absorption in the narrow ${ }^{3} P_{1}$ line is always found larger than in the two broad lines as shown in the right of figure 1 . The experimental result is exactly opposite in giving an absorption of $70 \%$ for the ${ }^{1} \mathrm{P}_{1}$ and ${ }^{3} \mathrm{D}_{1}$ lines, and close to zero or even negative for the ${ }^{3} \mathrm{P}_{1}$ line [1-5]. The anomalous intensities exhibited by these lines in the dense zone of a laser produced plasma cannot therefore be interpreted by various reabsorption values in an external plasma shell in conjoncture with an equilibrium of the populations in the upper level of the transitions. In order to account for the anomalies, it must be assumed that the ${ }^{3} P_{1}$ level is very much more populated than the ${ }^{1} P_{1}$ and ${ }^{3} \mathrm{D}_{1}$ levels.

We proposed to explain the extra population of the $2 s^{2} 2 p^{5} 4 d^{3} P_{1}$ level by a possible recombination channel from the $\mathrm{Al}^{4+}$ ion in its ground state via the $2 s 2 p^{6} 4 p{ }^{3} P_{1}$ autoionizing level [2-5]. We therefore attempted to identify this level with others of the same Rydberg's series in the spectrum of the plasma [2]. In figure 2 one can see, at a wavelength of $84.37 \AA$, an edge appearing in the continuous spectrum between several lines of more charged ions. As shown on the photographic recording of the spectrum, the edge is clearly restored by the upper densitometer trace : on the low energy side there is a strong absorption, while
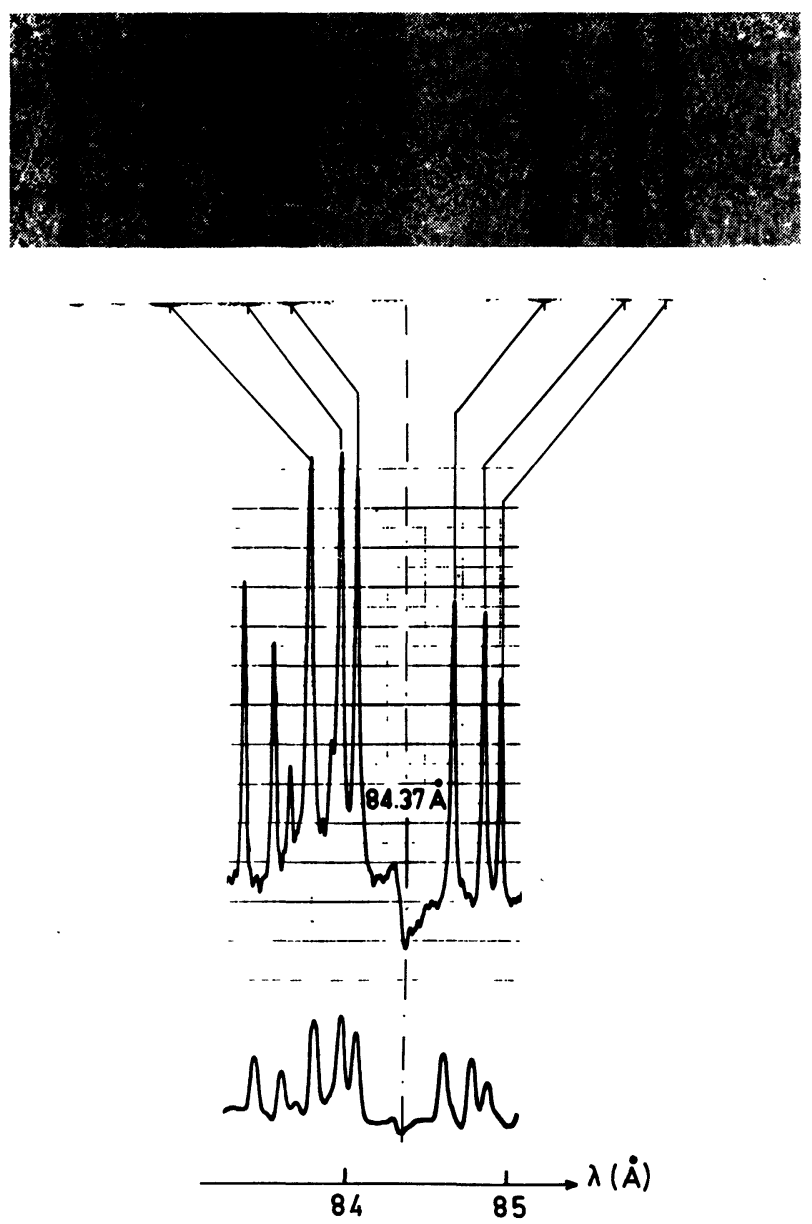

FIG. 2. - Comparison between the densitometer trace we have obtained (central part of the figure) and that reported from reference [9] (lower part). Our original photographic recording (upper part) shows emission lines of various $\mathrm{Al}$ ions and, at $84.37 \AA$, the photoabsorption structure corresponding, for the $\mathrm{Al}^{3+}$ ion, to the transition from the fround level to the $2 s 2 p^{6} 4 p{ }^{3} P_{1}$ autoionizing level. 
on the high energy side the absorption drops sharply. The energy position of the edge is close to that calculated for the $\mathrm{Al}^{3+}$ ion $2 \mathrm{~s} 2 \mathrm{p}^{6} 4 \mathrm{p}^{3} \mathrm{P}_{1}$ level [2]. The shape of the spectrum has been analyzed in terms of a Beutler-Fano profile [10] and exhibits a similarity with autoionizing structures observed in the neon spectrum [11]. The edge is also visible at exactly the same wavelength, on the lower trace in figure 2 as is reported from ref. [9] (although the author considered that there was no autoionizing structure in his spectra).
It is merely weaker than in our case, probably because of the use of a ruby-laser to produce the plasma instead of a neodymium laser. Indeed this leads to a lower intensity of the continuous spectrum in the extreme UV range [12]. But, as far as the edge is due to the photoabsorption from the ground state of the $\mathrm{Al}^{3+}$ ion to the $2 \mathrm{~s} 2 \mathrm{p}^{6} 4 \mathrm{p}^{3} \mathrm{P}_{1}$ level, one sees that such an observation needs the continuous spectrum to be as strong as possible.

\section{References}

[1] Carillon, A., Jaeglé, P., Jamelot, G., Sureau, A., Dhez, P., CukIER, M., Phys. Lett. 36A (1971) 167.

[2] Carillon, A., Jamelot, G., Sureau, A., Jaeglé, P., Phys. Lett. 38A (1972) 91.

[3] Carillon, A., Jaeglé, P., Jamelot, G., Sureau, A., Proceedings of the International Conference on Inner Shell Ionization Phenomena and Future Applications, Atlanta (U.S.A.) (1972) : Conf. 720404, 2373, 1973, U.S. A.E.C. Oak Ridge Tennessee.

[4] Carillon, A., Thèse $n^{\circ}$ AO8424, Paris (1973).

[5] Jaeglé, P., Carillon, A., Jamelot, G., Sureau, A., Proceedings of the IIId Vavilov Conference on Non Linear Optics, Novossibirsk ; edited by the Semiconductor Physics Institute of the Acad. of Sciences of U.S.S.R. Novossibirsk (USSR) (1973) p. 30.

[6] Carillon, A., Jamelot, G., Jaeglé, P., Sureau, A., Proceed- ings of the IVth Int. Conference on Vacuum Ultraviolet Radiation Physics, Hamburg (G.F.R.); edited by E.E. Koch, R. Hänsel, C. Kunz (Pergamon Viewed) 1974, p. 50.

[7] Jaeglé, P., Jamelot, G., Carillon, A., Sureau, A., Dhez, P., Phys. Rev. Lett. 33 (1974) 1070.

[8] Sureau, A., Proceedings of the Int. Conference on Inner Shell Ionization Phenomena and Future Applications, Atlanta (USA) (1972), Conf. 720404, 430, 1973, U.S. A.E.C. Oak Ridge, Tennessee.

[9] Valero, F. P. J., Appl. Phys. Lett. 25 (1974) 64.

[10] JAEGLÉ, P., Phys. Fenn. 9 (1974) 389.

[11] Codling, K., Madden, R. P., Ederer, D. L., Phys. Rev. 155 (1967) 26.

[12] Dhez, P., Jaeglé, P., Leach, S., Velghe, M., J. Appl. Phys. 40 (1969) 2545. 